\title{
Lupus Nephritis: Novel Treatments and Diagnostic Approaches
}

\author{
Namrata G. Jain - Elizabeth A. K. Hunt • \\ Elahna Paul • Michael J. G. Somers
}

Published online: 19 December 2012

(C) Springer Science + Business Media New York 2012

\begin{abstract}
Over the last decade, therapy for lupus nephritis in children has begun to shift from the provision of long-term steroids and intravenous cyclophosphamide to regimens with limited or no cyclophosphamide, lower steroid burdens, and increased reliance on oral mycophenolate mofetil. As the molecular immunology underlying the pathophysiology of lupus is further discerned, more targeted therapies, including the use of monoclonal antibodies against immune cells or cell signaling factors, may come to play a larger role in the treatment of pediatric lupus. Similarly, as experience with autologous stem cell transplantation for therapy-resistant disease is gained in adults, its potential applicability to such situations in children may be clarified. Over the next few decades, children with lupus will benefit as well from the identification of new biomarkers that are both sensitive and specific to disease activity, allowing clinicians to more readily assess response to therapy and diagnose disease flare.
\end{abstract}

Keywords Lupus nephritis - Systemic lupus erythematous (SLE) · Cyclosporine (CSA) · IVCY · MMF . Rituximab · Belimumab

Namrata G. Jain and Elizabeth A. K. Hunt contributed equally to this work.

N. G. Jain · E. A. K. Hunt · M. J. G. Somers $(\bowtie)$

Division of Nephrology, Boston Children's Hospital,

300 Longwood Avenue, Boston, MA 02115, USA

e-mail: michael.somers@childrens.harvard.edu

N. G. Jain · E. A. K. Hunt · E. Paul · M. J. G. Somers

Department of Pediatrics, Harvard Medical School,

Boston, MA, USA

E. Paul

Division of Pediatric Nephrology, MassGeneral

Hospital for Children, Boston, MA, USA

\section{Introduction}

About $20 \%$ of systemic lupus erythematous (SLE) is diagnosed before 18 years of age [1], and pediatric-onset SLE tends to present with more severe symptoms, is more likely to have concomitant renal involvement [2], and often requires more immunosuppression for effective treatment [3]. Despite such differences between adult and pediatric SLE, the approach to care for children with SLE has historically been modeled on treatments used in adults. In fact, most large series reporting treatment efficacy and all randomized controlled trials comparing therapies have been done primarily with adult subjects, underscoring the need for larger pediatric-specific clinical trials to delineate optimal approaches to childhood SLE.

In the absence of such trials, however, pediatric SLE therapy is likely to continue to parallel adult care, with particular interest not only in developing more molecularly-targeted treatments for systemic disease but also in identifying biomarkers that can be used with reliability to assess disease activity and treatment efficacy. Accordingly, in this review, we will focus on novel therapeutic and diagnostic approaches under consideration in the patient with SLE that are likely to be applicable to children, emphasizing particularly any pediatric data that may also exist for these endeavors.

\section{New Approaches with Oral Immunosuppression}

Throughout the last decades of the twentieth century, SLE outcomes-especially related to renal function-improved dramatically as regimens based on the use of long-term intravenous cyclophosphamide (IVCY) were introduced [4]. The significant adverse effects associated with IVCY, 
most notably its impact on fertility, infection, and secondary malignancy, resulted in the development of alternative regimens that spared duration of IVCY exposure or its cumulative dosing. For instance, the Euro-Lupus Nephritis Trial showed that a shorter course of lower dose IVCY followed by maintenance oral azathioprine (AZA) was as effective as long-term IVCY both initially [5] and at 10 year follow up [6•].

Over the last 15 years, in an attempt to see if IVCY exposure could be reduced further or even eliminated, induction and maintenance regimens utilizing oral mycophenolate mofetil (MMF) have been studied. The ALMS trial was the largest randomized controlled trial comparing MMF to IVCY over a 24 week induction period. It included 370 ethnically and geographically diverse patients with WHO class III-V lupus nephritis. Subjects received either $3 \mathrm{~g} /$ day of oral MMF or monthly IVCY pulses $\left(0.5-1 \mathrm{~g} / \mathrm{M}^{2}\right)$ with both groups receiving oral steroids. There was no significant difference in treatment response at 24 weeks defined as a decrease in urine protein/creatinine ratio (to nonnephrotic range in subjects with baseline nephrotic-range proteinuria or a decrease in proteinuria by $50 \%$ in subjects with non-nephrotic proteinuria at baseline) as well as stabilization or improvement in serum creatinine. Adverse events were also not significantly different between groups $[7 \cdot \bullet]$.

In another trial of 140 adults with WHO class III-V lupus nephritis, a similar treatment protocol was used. The primary endpoint was complete remission, which was defined as return to within $10 \%$ of normal values for serum creatinine and proteinuria as well as an inactive urinary sediment. On intention to treat analysis, MMFtreated subjects had increased rates of complete remission ( 25 vs. $5.8 \%, p=0.005$ ) as well as fewer severe infections. There was also a trend towards a higher rate of partial remission in the MMF group. Three years after induction therapy, the MMF group also had lower rates of ESRD and death than the IVCY group. There were concerns, however, that outcomes had not been analyzed for important confounding variables such as maintenance therapy (this was not standardized in any fashion), race, and withdrawal from trial due to adverse sequelae [8].

Two other recent large studies have focused particularly on maintenance therapy routines after induction, one showing equivalent results with maintenance MMF or AZA [9] and another, which was a continuation of the ALMS trial, showing superiority of maintenance oral MMF compared to AZA in decreasing relapse rates [10].

The long-term effects of variations in induction and maintenance regimens are not well understood. A retrospective review from Korea showed no difference in initial remission rates for lupus nephritis between oral MMF and IVCY, but after 10 years there was a significantly decreased risk for ESRD and mortality in the IVCY group, despite the fact that the IVCY group initially had evidence of more nephritis [11]. Conversely, in a Dutch population treated with either oral AZA or IVCY induction and then maintenance AZA over a median follow-up of nearly 10 years, there was no difference in rates of ESRD, mortality, or sustained doubling of serum creatinine between the two regimens, despite more renal relapses on follow-up in AZAtreated subjects [12].

Although there are no randomized controlled studies to specifically evaluate oral MMF or AZA versus IVCY for induction in children, the ALMS trial included 24 children. Review of the outcomes in these pediatric patients showed a trend towards benefit from MMF induction as well as MMF maintenance compared to AZA [13•]. In addition, a retrospective review of 138 children treated between 1980 and 2010 also suggested improved outcomes with the addition of MMF as induction or maintenance therapy [14].

Another area warranting further investigation is the relationship between specific clinical variables such as race and treatment response to MMF and whether data that has been generated again largely in adults applies similarly to children. Most SLE studies have been underpowered to analyze outcomes by race, and single center experiences often have a homogeneous population for that geographic or referral area. When the ALMS study was re-examined by race, white and Asian groups had similar rates of response to IVCY and MMF, but the black and Hispanic groups had better response to MMF [15]. A meta-analysis of 11 studies from around the world found that overall there was no statistical difference in remission rates between MMF and IVCY, although, again, studies outside of Asia showed more benefit with MMF [16]. These data suggest that future investigations should consider race and geographical location as confounding variables in assessing response.

Thus, there is good evidence that MMF is at least equivalent to and, especially in Black and Hispanic SLE patients, may be better than IVCY for induction. After short-term follow up, it also appears that MMF is favorable in terms of adverse effects. These results, coupled with the safety profile of MMF in children that has been established by its widespread use in pediatric renal transplantation, support MMF as a reasonable choice in pediatric SLE and many clinicians are now considering MMF as first-line therapy for induction and maintenance therapy.

A significant caveat for clinicians caring for children with SLE is adherence to a regimen that requires several doses daily of a medication for a long period of time. Given that most young children and many adolescents must rely on adult caregivers to obtain and provide oral medications, in situations where there is concern that the child will not receive oral medications as prescribed, IVCY should be 
considered. Similarly, in adolescents with demonstrated non-adherence to prescribed medication regimens, IVCY insures that medication is provided and may need to be maintained until there is evidence of improved behavior.

Cyclosporine (CSA), a calcineurin inhibitor that inhibits $\mathrm{T}$ cell proliferation, has been a mainstay of solid organ transplantation for nearly three decades. Several studies suggest that it may also be beneficial in SLE. A multicenter open label randomized controlled trial evaluated 40 subjects with newly diagnosed WHO class III or IV lupus nephritis induced with IVCY or CSA. Remission and response rates were not significantly different and, after a mean 40 months follow up, relapse-free survival was similar between groups [17]. Another multicenter open label randomized controlled trial with 89 patients compared AZA and CSA in patients who required changes in their treatment regimen and found no difference between groups in prednisone dose, disease activity scores, or number of flares or adverse effects [18]. Another study with 42 adults with lupus membranous nephropathy compared prednisone alone, CSA, and everyother-month IVCY for 11 months. After 1 year of followup, the probability of remission was significantly higher in the IVCY (60\%) and CSA (83\%) groups compared to the prednisone only group $(27 \%)$, with a tendency towards faster remission in the CSA group. After median follow-up of 60 months, however, the risk of relapse was higher in the CSA group compared to the IVCY group, though there were differences in the racial composition of the groups that likely confounded these results [19].

There are also reports supporting CSA use in children. A retrospective review of 16 children with class III/IV lupus nephritis, most of whom were treated with MMF, methylprednisolone, and CSA had overall good responses, although the treatment regimens were variable. At initiation, five patients required dialysis but all of them were off dialysis with good eGFR $>80 \mathrm{~mL} / \mathrm{min} / 1.73 \mathrm{M}^{2}$ at 12 month follow up [20]. CSA use has also been reported in treatment of refractory proteinuria in children with SLE, and its use resulted in a significant decrease in protein excretion although relapse was common after discontinuation [21].

Overall, it appears that CSA may be beneficial in SLE, but there is no evidence to support its specific use over other therapies such as oral MMF, especially in children. Moreover, a significant sequela of calcineurin inhibitor provision is nephrotoxicity with irreversible parenchymal scarring, so its long-term use should be avoided in any SLE population.

Tacrolimus, another calcineurin inhibitor that has largely supplanted CSA in solid organ transplantation, has also been used as therapy for lupus nephritis. In vitro studies using human peripheral blood mononuclear cells showed that low concentrations of tacrolimus inhibited production of TNF $\alpha$ and IL-1 $\beta$, thus prompting interest in its usage in SLE [22]. A recent meta-analysis reviewed five randomized controlled trials including 225 patients with SLE who were induced with either tacrolimus or IVCY and found that the tacrolimus group had increased rate of complete remission (RR 1.61, $p=0.004$ ), higher overall response rates, lower disease activity scores, and decreased levels of proteinuria. They also had fewer GI symptoms and menstrual irregularities. Other adverse results such as infection were not statistically different between groups [23]. The ability to generalize from these results to children is limited, however, by the fact that the majority of participants were Asian adults and follow up was for only a mean of 6 months.

The utility of tacrolimus is supported in another metaanalysis that included one randomized controlled trial, one case control study, and five open label studies [24]. Other smaller studies have also supported using tacrolimus as rescue therapy in patients with diffuse proliferative or membranous lupus nephritis [25]. A multicenter randomized controlled trial comparing AZA and tacrolimus for maintenance (both with prednisone) showed no statistical difference between outcomes in the two groups, but there were lower rates of leukopenia in the tacrolimus group [26]. An open label study of 60 patients with SLE showed no significant difference in remission rates in patients induced with MMF, IVCY, or tacrolimus. There was a trend towards more infections in the MMF and IVCY group and more hyperglycemia in the tacrolimus group, but no overall difference in adverse events [27].

These studies suggest that tacrolimus may be considered for induction, maintenance or treatment of lupus. Since the majority of studies have been performed in Asians and there is racial variation in SLE treatment response, it would require further study in more diverse populations including children to make more definitive conclusions as to the efficacy of tacrolimus in pediatric SLE. Also, like CSA, tacrolimus provision can be complicated by nephrotoxicity, and this needs to be considered in its provision versus other therapies such as MMF with apparent similar efficacy.

Rapamycin or sirolimus, an mTOR inhibitor that is currently used as immunosuppression for solid organ transplantation, has also been tested in pilot studies for treatment of lupus nephritis. One small series noted a generalized improvement in lupus activity scores [28]. Currently two phase 2 trials are active, with treatment groups including children $>13$ years of age [29]. Again, based on experience in children with renal transplantation, rapamycin tends to be well tolerated, though many children do require concomitant therapy for drug-related hyperlipidemia. Unlike the calcineurin inhibitors CSA and tacrolimus, mTOR inhibitors such as rapamycin are not nephrotoxic so they may be a more attractive alternative if further study continues to show efficacy. 
Table 1 B cell therapies studied in treatment of systemic lupus erythematosus

\begin{tabular}{|c|c|c|c|}
\hline B cell therapies & Target mechanism & Clinical trial* (phase) & Effect/status \\
\hline Rituximab & $\begin{array}{l}\text { Chimeric mAb targeting CD20 } \\
\text { on immature B-cells }\end{array}$ & $\begin{array}{l}\text { LUNAR }^{*}:(\text { phase } 3) \\
\text { EXPLORER*: (phase 2/3) }\end{array}$ & 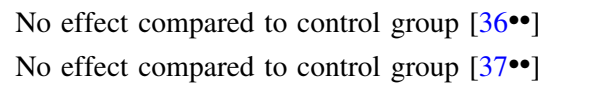 \\
\hline Ocrelizumab & $\begin{array}{l}\text { mAb targeting } \mathrm{CD} 20 \text { on peripheral } \\
\mathrm{B} \text { cells }\end{array}$ & 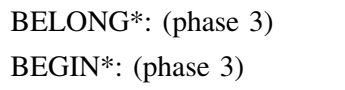 & $\begin{array}{l}\text { Active not recruiting } \\
\text { Terminated }\end{array}$ \\
\hline Abetimus & $\begin{array}{l}\text { Synthetic toleragen specific for } \\
\text { anti-dsDNA; induces B cell tolerance }\end{array}$ & $\begin{array}{l}\text { ASPEN } * *:(\text { phase } 3) \\
\text { Phase } 3 * *\end{array}$ & $\begin{array}{l}\text { Terminated, lack of efficacy } \\
\text { Decreased anti-dsDNA levels but did } \\
\text { not prolong time to renal flare [46] }\end{array}$ \\
\hline Belimumab & $\begin{array}{l}\text { Humanized mAb against B-lymphocyte } \\
\text { co-stimulator (BLyS) with effect on } \\
\text { TNF-alpha pathway }\end{array}$ & $\begin{array}{l}\text { BLISS-52 and BLISS-76: } \\
\text { (phase 3) } \\
\text { BLISS-LN: (phase 3) }\end{array}$ & $\begin{array}{l}\text { Improvement in disease activity } \\
\text { scores }[41,42] \\
\text { Active and recruiting }\end{array}$ \\
\hline Bortezomib & Proteasome inhibitor & Phase 4 & Withdrawn \\
\hline Epratuzumab & Humanized $\mathrm{mAb}$ targeting $\mathrm{CD} 22$ & $\begin{array}{l}\text { Pilot } \\
\text { EMBLEM: (phase 2) } \\
\text { Phase } 3\end{array}$ & $\begin{array}{l}\text { Improved disease activity scores [43] } \\
\text { Awaiting results } \\
\text { Multiple trials active and recruiting }\end{array}$ \\
\hline BG9588 & Anti-CD40 ligand antibody & Phase 2 & $\begin{array}{l}\text { Improved disease activity scores, but study } \\
\text { terminated due to thromboembolic events [47] }\end{array}$ \\
\hline
\end{tabular}

A phase 2 trial of 110 subjects, including adolescents at least 16 years old, has shown promise for leflunomide, an immunomodulator that inhibits pyrimidine synthesis [30]. Compared to subjects who received traditional treatment with IVCY and steroids, those treated with leflunomide demonstrated significant reductions in active renal lesions on re-biopsy at 6 months. A phase 3 trial combining tacrolimus with leflunomide is currently ongoing [29].

\section{Novel Therapies Targeting B Cells}

Enhanced understanding of immunologic factors mediating SLE has allowed for the use and development of therapies that are more molecularly targeted. Due to the prominent role of autoantibodies against DNA, ribonucleoprotein, chromatin, and platelets in SLE, the loss of B cell tolerance has been implicated as a pathogenic cause of disease, and B cell clusters have been identified in renal biopsies of lupus nephritis [31,32]. Thus, an increasing number of therapies targeting B cell mechanisms have been the focus of study (Table 1).

Rituximab, a chimeric mouse-human monoclonal antibody to CD20 antigen, targets immature, naïve, germinal center, memory B cells but not plasma cells [33]. Data from several European cohorts noted improvement of both serum albumin and proteinuria in patients with lupus nephritis who were treated with rituximab for refractory disease [34•]. Similarly, a multicenter review of 116 subjects with refractory lupus noted more than $60 \%$ response (19\% complete remission and $44 \%$ partial remission) to rituximab at 6 months [35].

In contrast to this experience, two large phase 3 trials showed no benefit from rituximab therapy. The LUNAR trial evaluated the effect of adding rituximab ( $1 \mathrm{~g}$ IV infusion on days $1,15,168,182)$ to $\mathrm{MMF} /$ steroid treatment in 114 SLE patients with class III/IV nephritis over a 1 year period. MMF was initially provided at $1.5 \mathrm{~g}$ per day and increased to $3 \mathrm{~g}$ per day by week 4 . IV methylprednisolone was initially provided at day 1 and 3 for active nephritis and later changed to oral prednisone $0.75 \mathrm{mg} / \mathrm{kg} /$ day until day 16 , with subsequent taper to $<10 \mathrm{mg}$ /day by week 16 . Renal response rates were not significantly different $(45.8 \%$ in the MMF/steroid group and $56.9 \%$ in the Rituximab group). Although there was no difference in primary endpoints, rituximab therapy reduced anti-dsDNA, $\mathrm{C} 3$ and $\mathrm{C} 4$ levels [36••].

Similarly, in the EXPLORER trial which included 257 SLE patients with extra-renal manifestations followed over a year period, rituximab treatment (two IV doses of $1 \mathrm{~g}$ at time of entry and at 6 months) added to steroid therapy did not change the frequency of moderate to severe lupus flares. Pre-study immunosuppression regimens were continued (MMF, methotrexate, or azathioprine) and prednisone was initially increased at entry to study and then tapered to $<5 \mathrm{mg} /$ day by week 52 . A sub-analysis suggested that there might have been more benefit to rituximab provision in African Americans and Hispanics than other 
Table 2 Non-B cell therapies in treatment of systemic lupus erythematosus

\begin{tabular}{|c|c|c|c|}
\hline Additional SLE therapies & Target mechanism & Clinical trial* (phase) & Effect/status \\
\hline \multirow[t]{3}{*}{ Abatacept } & \multirow{3}{*}{$\begin{array}{l}\text { Fusion protein inhibiting } \\
\text { co-stimulation between } \\
\text { CD28/CD80 }\end{array}$} & ACCESS* & Active not recruiting \\
\hline & & Phase 2 & $\begin{array}{l}\text { Not effective versus control in decreasing } \\
\text { new flares with steroid taper [53] }\end{array}$ \\
\hline & & Phase $2 / 3$ & Terminated: lack of efficacy \\
\hline \multirow[t]{3}{*}{ Rapamycin } & \multirow[t]{3}{*}{ mTOR inhibitor } & Pilot & Improvement in disease activity scores [28] \\
\hline & & Phase $2 * *$ & Awaiting results \\
\hline & & Phase 2 & Active and recruiting \\
\hline Tocilizumab & Humanized mAb against IL-6R & Phase 1 & $\begin{array}{l}\text { Decreased disease activity scores in } 8 \\
\text { out of } 16 \text { patients [48] }\end{array}$ \\
\hline \multirow[t]{2}{*}{ Sirukumab (CNTO 136) } & \multirow[t]{2}{*}{ Humanized mAb against IL-6 } & Phase 1 & Well tolerated safety profile [49] \\
\hline & & Phase 2 & Active and recruiting \\
\hline \multirow[t]{2}{*}{ Infliximab } & \multirow[t]{2}{*}{$\mathrm{mAb}$ against TNF alpha } & Pilot & $\begin{array}{l}\text { In trial of } 9 \mathrm{LN} \text { patients, } 6 \text { responded with } \\
\text { concomitant azathioprine [51] }\end{array}$ \\
\hline & & TRIAL: (phase 2/3) & Terminated: failure to recruit \\
\hline \multirow[t]{2}{*}{ Leflunomide } & \multirow[t]{2}{*}{$\begin{array}{l}\text { Immunomodulator that inhibits } \\
\text { pyrimidine synthesis }\end{array}$} & Phase $2 / 3 *$ & $\begin{array}{l}\text { No significant difference vs. } \\
\text { cyclophosphamide }+ \text { steroids [30] }\end{array}$ \\
\hline & & Phase 3 & Active and recruiting \\
\hline \multirow[t]{2}{*}{ Sifalimumab (MEDI-545) } & \multirow[t]{2}{*}{$\begin{array}{l}\text { Humanized mAb against } \\
\text { Anti-IFN-alpha }\end{array}$} & Phase 1 & $\begin{array}{l}\text { Decreased clinical activity with single } \\
\text { injection }[55,56]\end{array}$ \\
\hline & & Phase 2 & $\begin{array}{l}\text { Multiple trials active, recruiting, or awaiting } \\
\text { results }\end{array}$ \\
\hline \multirow[t]{2}{*}{ Rontalizumab } & \multirow{2}{*}{$\begin{array}{l}\text { Humanized mAb against } \\
\text { Anti-IFN-alpha }\end{array}$} & Phase 1 & Acceptable safety profile [57] \\
\hline & & ROSE: (phase 2) & Active not recruiting \\
\hline \multirow[t]{2}{*}{ Rigerimod (Lupuzor) } & \multirow[t]{2}{*}{$\begin{array}{l}\text { Spliceosomal peptide } \mathrm{P} 140 \\
\text { recognized by CD } 4+\mathrm{T} \text { cells }\end{array}$} & Phase 2 & $\begin{array}{l}\text { Improved disease activity scores and } \\
\text { decreased anti-ds DNA levels [59] }\end{array}$ \\
\hline & & Phase 3 & Recently approved to start future trial in USA \\
\hline IFNa-Kinoid (vaccine) & Induce antibodies to IFN-alpha & Phase $1 / 2$ & Active not recruiting \\
\hline
\end{tabular}

Unless specifically stated otherwise in text, status of all clinical trials referenced from www.Clinicaltrials.org [29]

* Indicates inclusion of adolescents $>16$ years

** Indicate inclusion of children and adolescents $>13$ years

$m A b$ monoclonal antibody, $T N F$ tumor necrosis factor, IFN interferon, $m T O R$ mammalian target of rapamycin

groups [37••]. This data underscores that particular patient subsets may be impacted differently than the entire treatment group and that these factors may need to be considered in tailoring individual therapy.

Given these results, rituximab is not now recommended over standard therapy with steroids and MMF or IVCY in the initial treatment of lupus nephritis. Care must be taken regarding its use in refractory lupus as well, given concerns regarding an increased risk of progressive multifocal encephalopathy (PML) from reactivation of the JC virus, which has prompted an FDA alert [38] about its use. A recent 6 year review of the US Adverse Reporting System demonstrated 124 PML cases associated with Rituximab out of a total of 635 PML cases [39].

Ocrelizumab, an anti-CD20 antibody that primarily targets peripheral B cells (thus sparing the immature B cells targeted by rituximab), was first studied for treatment of rheumatoid arthritis and is now also been studied in lupus nephritis with the phase 3 BELONG trial [40]. It compares the addition of ocrelizumab to standard therapy (corticosteroids, MMF, and cyclophosphamide) with standard therapy alone [29] and results from this trial may elucidate if there is a particular advantage to this alternative approach to $\mathrm{B}$ cell depletion.

Belimumab, a monoclonal antibody against B-lymphocyte co-stimulator (BLyS), has shown promise in two randomized placebo-controlled trials of nearly 1,700 subjects [31, 41, 42]. BLyS seems to play a key role in B cell development and survival and has been found to be overexpressed in SLE. After a year, use of belimumab at doses of 1 and $10 \mathrm{mg} / \mathrm{kg}$ was associated with improved lupus disease activity scores, including specific renal symptoms [41, 42]. A phase 3 belimumab study is currently recruiting SLE patients with active renal disease [29]. 
Epratuzumab, a humanized anti-CD22 monoclonal antibody, resulted in improved lupus activity scores in an openlabel single center study of 14 moderately severe SLE patients [43]. CD22 is a regulatory molecule that is thought to play a role in immune over activation. In another trial, epratuzumab doses of $600 \mathrm{mg}$ weekly significantly improved lupus activity scores [44]. Multiple phase 2 and 3 clinical trials are currently recruiting [29].

Animal studies have indicated a decrease in circulating anti-dsDNA levels with abetimus sodium, a tolerogen that can both block specific B cell anti ds-DNA antibodies and complex them together [45]. A 22 month study of 317 SLE patients showed reduced serum anti-dsDNA levels with weekly $100 \mathrm{mg}$ Abetimus doses as well as $>50 \%$ reduction in proteinuria after a year, though treatment did not significantly prolong time to renal flare [46].

BG9588, an anti-CD40 ligand antibody that should result in decreased production of autoantibodies, was evaluated in a phase 2 clinical trial that included 28 patients. It showed promise by decreasing anti-ds DNA levels and hematuria, but the trial was terminated prematurely due to an increased rate of thromboembolic events [47]. No further studies have been reported with its use [29].

\section{Therapies Targeting Cell Signaling Molecules}

Several novel molecular agents targeting cell signaling molecules that play a key role in inflammatory response with autoimmune disorders have also been developed and are increasingly being studied both as primary approaches or adjunctive treatments for SLE. These treatments, including a novel vaccine to induce antibodies to interferon-alpha (IFN-a) to mitigate inflammatory processes, are listed in Table 2, with further detail below of applicable clinical trials.

Tocilizumab, a monoclonal antibody to Interleukin-6 receptor (IL-6R), has been evaluated in a phase 1 openlabel dose escalation study $(2,4$, or $8 \mathrm{mg} / \mathrm{kg})$ in 16 subjects with mild to moderate disease activity, including patients with chronic glomerulonephritis unresponsive to 6 months of immunosuppressive therapy [48]. Significant improvements in disease activity scores were noted in half, as well as decreases in anti-dsDNA levels and circulating plasma cells. Tocilizumab dose escalations were associated, however, with decreasing neutrophil counts. Sirukumab, a monoclonal antibody to IL-6 that is being used in an active phase 2 lupus nephritis trial [29], has also been found to induce similar neutropenia [49].

Infliximab, a monoclonal antibody against tumor necrosis factor (TNF-alpha), has proven efficacy against immunologically-mediated disease processes such as inflammatory bowel disease [50], leading to trials of its use with SLE. In one small series of SLE patients treated with four doses of infliximab and maintenance oral azathioprine, two-thirds manifested a sustained remission of lupus nephritis at 5 years follow-up [51], but adverse sequelae such as CNS lymphoma and legionella pneumonia were also seen. Given further data associating the combination of thiopurines and TNF-alpha inhibitors with T cell non-Hodgkin's lymphomas [52], interest in this approach has waned and several trials that had been actively recruiting patients have been terminated [29].

Abatacept is a fusion protein composed of the Fc region of immunoglobulin IgG fused to CTLA-4. It inhibits CD28 co-stimulation of $\mathrm{T}$ cells, thereby preventing full activation of T cells. One trial of 175 SLE patients provided abatacept showed no significant difference in rates of systemic lupus flares versus conventional therapy over a 12 month period [53]. Another phase 2 trial examining abatacept in active lupus nephritis (ACCESS trial) has completed recruiting and results are pending [29]. Use of belatacept, an immunomodulator with a mechanism of action similar to abatacept, was favorably compared to CSA in kidney transplant patients in the large phase 3 BENEFIT-EXT trial. Belatacept has been associated, however, with increased rates of post-transplant lymphoproliferative disorder (PTLD) and tuberculosis [54]. As a result, there has not been decreased consideration of its use in other clinical conditions such as SLE where multiple immunomodulators may be used similar to transplantation.

Studies for sifalimumab (MEDI-545) and rontalizumab, monoclonal antibodies to IFN-alpha that also inhibit induction of IFN mRNAs, have shown promise in phase 1 trials $[55,56]$. Sifalimumab was shown to decrease signs and symptoms of lupus activity after a single injection without reactivation of viral infections. Rontalizumab has also demonstrated an acceptable safety profile [57] and is being studied in a phase 2 trial [29].

Rigerimod, also known as lupuzor, is a therapy consisting of a spliceosomal P140 peptide that is recognized by $\mathrm{CD} 4+\mathrm{T}$ cells. Its use is supposed to reduce $\mathrm{T}$ cell proliferation, and it may have the potential to induce tolerance [58, 59]. A European phase 2 open-label study of 20 subjects with SLE showed improved disease activity scores and a decrease in anti-ds DNA titers in the majority of patients after three subcutaneous doses [59]. It has recently been approved by the USA FDA to enter phase 3 clinical trials [60].

\section{Stem Cell Transplantation}

Stem cell transplant (SCT) has also been considered as a potential therapy for refractory rheumatological 
diseases such as SLE [61•]. The goal of SCT would be the elimination of auto-reactive lymphocytes and the subsequent production of new self-tolerant cell lines. Compared to allogeneic transplant, autologous SCT has significantly lower mortality [62] and, accordingly, has become the preferred approach for refractory autoimmune disease [63].

SCT can be sourced from mesenchymal or hematopoietic cell lines. Mesenchymal cells (MSCs), typically harvested from bone marrow, adipose, or umbilical cord, not only have the potential to differentiate into non-hematopoietic cells types but also lack significant immunogenicity so that pre-SCT conditioning regimens may be unnecessary $[61 \bullet, 64]$. MSCs have low levels of HLA class 1 major histocompatibility complex and are also negative for class II MHC co-stimulator molecules such as CD80, CD86, and CD40 that have been implicated in SLE pathogenesis [65, 66]. In comparison, hematopoietic stem cells (HSC) require aspiration from bone marrow or mobilization from peripheral blood with cyclophosphamide or granulocyte stimulating factors prior to harvesting via apheresis [67]. For HSC transplants, infused cells are further selected for CD34 positivity to eliminate $\mathrm{T}$ cells and decrease immunogenicity [68].

A retrospective review of European registry data for autologous SCT included outcomes in 53 SLE patients who manifested a disease remission rate of $66 \%$ at 6 months, but subsequent relapse then occurred in $32 \%$ [62]. There were also 12 deaths occurring from 0 to 48 months after transplant. In a corresponding American SCT registry, 48 patients with refractive SLE demonstrated 5 year patient survival of $84 \%$, although probability of disease-free survival was only $50 \%$ [69]. Improvements were noted, however, in disease activity scores, and serum anti-dsDNA, complement, and ANA levels.

Autologous transplant does not, however, remove a patient's underlying genetic susceptibility to autoreactivity, thus allowing the potential for relapse of an underlying autoimmune disease by the re-formation of auto-aggressive lymphocyte clones [70]. Along those lines, nearly half the deaths reported in autologous SCT patients with SLE were not a result of the transplant itself; rather, a large proportion died from active SLE despite the SCT [71, 72]. Such results have complicated the ability to recruit patients to more rigorously assess this treatment versus conventional therapy in randomized controlled trials [29].

The specific role that SCT plays in refractory pediatric SLE therapy remains unclear. Given the less than sanguine results to date in adults, most pediatric clinicians would like to see decreased SCT-related morbidity and mortality and more widespread and sustained therapeutic efficacy before its consideration ahead of other novel therapies in children with therapy-refractory disease.

\section{Diagnostic Biomarkers of Lupus Nephritis}

Complicating the assessment of any therapy in SLE is the clinician's ability to assess disease activity. For instance, the gold standard for diagnosis and classification of lupus nephritis is still the renal biopsy. Other less invasive ways to assess renal lupus activity such as quantifying urinary protein, reviewing the urinary sediment, assessing serum creatinine or $\mathrm{C} 3$ and $\mathrm{C} 4$ complement levels, or measuring anti-dsDNA titers, while useful in clinical context are all limited in their abilities to determine the presence or extent of renal involvement. A recent report exemplifies the inadequacy of current clinical assessment: in a cohort of SLE patients with no evidence of renal involvement in the way of significant proteinuria, increased serum creatinine, or active urinary sediment, nearly $50 \%$ actually had lupus nephritis on biopsy [73••].

Since biopsies are invasive, involve risk, and are not practical for disease surveillance, there is impetus to identify and validate biomarkers that permit diagnosis and assessment of lupus nephritis activity. In addition, biomarkers for renal lupus or generalized SLE activity could be used to assess response to therapy in a more precise manner than current clinical assessments.

Chemokine ligand 2 (CCL2), also known as monocyte chemo-attractant protein-1 (MCP-1), has been investigated as a putative biomarker for SLE. CCL2/MCP-1 is a chemokine that preferentially attracts monocytes and memory $\mathrm{T}$ lymphocytes and seems to enhance vascular permeability. Its glomerular expression is increased in children with more severe nephritis (class III/IV) [74] and several studies in adults have demonstrated a correlation between nephritis activity and urinary MCP-1 levels, including one report that demonstrated that MCP-1 increased from 2 to 4 months prior to a renal flare, subsequently decreasing in patients who responded to treatment while remaining elevated in non-responders [75]. In adults, urinary MCP-1 has not correlated with histologic findings on renal biopsy [76], though two pediatric studies showed correlation of urinary MCP-1 concentration with disease activity scores [77••, 78]. Longitudinal studies in children would be the next step to evaluate the ability of MCP-1 to predict flares in this population as well.

Neutrophil gelatinase-associated lipocalin (NGAL) is a member of the lipocalin family of binding proteins. Its expression in epithelial cells increases in response to inflammation [79] and it also seems to play a role in binding iron and exerting bacteriostatic effects [80]. NGAL expression in the kidney is also enhanced in response to acute kidney injury. NGAL has been detected in urine as soon as $6 \mathrm{~h}$ after cardiopulmonary bypass in children undergoing cardiac surgery, with levels correlating well with subsequent acute kidney injury [81]. In children with 
SLE, urinary NGAL is significantly higher in those with active renal disease, and NGAL was found to be both a sensitive and specific marker to discern biopsy-proven nephritis [82, 83].

This predictive value of urinary NGAL was illustrated in a report of 111 children with SLE followed at 3 month intervals. A significant increase in urinary NGAL was noted up to 3 months prior to confirmation of worsening renal disease by traditional clinical measures, with a high degree of sensitivity and specificity between NGAL and renal injury [84]. To date, levels of urinary NGAL have not been shown to correlate with specific renal histology subtypes, however, so milder changes may not be differentiated from more severe histopathology. Moreover, urinary NGAL can be elevated in the setting of other causes of renal injury, particularly complicating its use in children with SLE who may be acutely ill or have other risk factors for renal compromise.

Due to their roles in promoting leukocyte adhesion and data that suggests that their expression may be increased in biopsies of patients with active lupus nephritis, intracellular adhesion molecules (ICAMs) and vascular adhesion molecules (VCAMs) have also received attention as possible biomarkers in SLE [85]. In one study, urinary ICAM-1 and VCAM-1 were significantly elevated in those adult SLE patients with severe renal histological findings (WHO class III, IV and V) compared to those with less severe findings (WHO class I or II) [86]. In 24 patients who underwent concomitant renal biopsy and urine studies, urinary VCAM-1 levels were significantly elevated in those with biopsy-proven diffuse proliferative glomerulonephritis (WHO class IV) compared to other histologic changes. Urinary VCAM-1 levels also correlated with a disease activity index in biopsies. Interestingly, urinary VCAM-1 levels in patients with other active glomerular disease such as focal segmental glomerulosclerosis (FSGS), ANCA glomerulonephritis, and membranous nephropathy were similar to those in patients with active SLE, suggesting that it may have more broad applicability to nephritis in general [76].

Theoretically, a combination of biomarkers would improve the sensitivity and specificity of disease diagnosis and prognostication. In a proteomic signature (PS) developed from 32 pediatric SLE patients, several candidate urinary proteins correlated with overall disease activity. There was not similar correlation with histology findings, but urine was collected an average of 9 months after biopsy [87]. Within this PS, transferrin (Tf) and lipocalin-type prostaglandin-D synthetase (L-PGDS) were found to be significantly associated with active lupus nephritis [88].

In another attempt to use biomarkers to characterize disease activity in 76 patients (including 26 children), the combination of urinary MCP-1, AAG, $\mathrm{Cp}$, and urinary protein to creatinine ratio predicted lupus activity, and the combination of MCP-1, NGAL, and creatinine clearance predicted chronicity [89•]. Certain biomarker panels also seemed to correlate with biopsy histology findings as well, including membranous lupus nephritis (WHO class V) and interstitial inflammatory infiltrate [90].

Taken together, such results hint at the benefit of a validated biomarker panel to assist with the diagnosis and follow-up of children with lupus to more accurately assess disease activity. Characterizing response based on urinary biomarkers would simplify clinical management and allow for more readily individualized courses of therapy. Biomarkers would also facilitate the evaluation of new therapeutic interventions.

\section{Conclusion}

The approach to therapy in lupus continues to evolve, with an emphasis on identifying regimens that are efficacious and less toxic than the standard therapy that for so many years relied on steroids and cyclophosphamide, especially in the setting of lupus nephritis. At this point in time, the use of oral MMF as induction and maintenance therapy seems to offer both efficacy and decreased toxicity and, in many pediatric centers, is becoming first-line approach to therapy. Less intense or prolonged induction phases and more individually tailored maintenance therapy will certainly continue to characterize changes to SLE treatment over the next decade, especially in pediatric patients at particular risk for drug-associated morbidity.

As there is increased understanding of the immunologic derangements underlying disease pathogenesis in SLE, the use of therapies directed against cells or signaling molecules in the immune system is likely to become more common as well. At this point, there is not sufficient data to endorse the use of Rituximab, the most-studied of these agents in SLE, as a first-line adjunct in children. In children with recalcitrant disease to more standard approach, the results of uncontrolled studies and anecdotal reports may support its consideration, especially in African Americans or Hispanics who did seem to benefit more in controlled studies in adults. In considering any of these therapies, however, the clinician must also weigh the limited data on potential long-term toxicity of these agents, especially in children who may need significant further immunomodulatory therapy for future disease flares.

Additionally, as better biomarkers for SLE activity are discerned, they can be incorporated into clinical care, again allowing for a much more individualized therapeutic approach as well as improved and earlier recognition of disease flares. As with many pediatric diseases, experience in adults will continue to shape therapy for children with 
SLE, but there is the need to include children in studies assessing new SLE treatments or trying to validate new biomarkers so that their clinical care can be increasingly evidence-based.

Conflict of interest No potential conflicts of interest relevant to this article were reported.

\section{References}

Papers of particular interest, published recently, have been highlighted as:

- Of importance

•• Of major importance

1. Klein-Gitelman M, Reiff A, Silverman ED. Systemic lupus erythematosus in childhood. Rheum Dis Clin North Am. 2002;28: 561-77.

2. Costallat LT, Coimbra AM. Systemic lupus erythematosus: clinical and laboratory aspects related to age at disease onset. Clin Exp Rheumatol. 1994;12:603-7.

3. Brunner HI, Gladman DD, Ibañez D, et al. Difference in disease features between childhood-onset and adult-onset systemic lupus erythematosus. Arthritis Rheum. 2008;58:556-62.

4. Austin HA 3rd, Klippel JH, Balow JE. Therapy of lupus nephritis. Controlled trial of prednisone and cytotoxic drugs. N Engl J Med. 1986;314:614-9.

5. Houssiau FA, Vasconcelos C, D'Cruz D, et al. Immunosuppressive therapy in lupus nephritis: the Euro-Lupus Nephritis Trial, a randomized trial of low-dose versus high-dose intravenous cyclophosphamide. Arthritis Rheum. 2002;46:2121-31.

6. - Houssiau FA, Vasconcelos C, D'Cruz D, et al. The 10-year follow-up data of the Euro-Lupus Nephritis Trial comparing lowdose and high-dose intravenous cyclophosphamide. Ann Rheum Dis. 2010;69:61-4. This trial reports 10 year follow up of the Euro-Lupus trial (90 patients), which compared low vs. high dose IV CY induction followed by AZA maintenance. There was no difference in death, doubling of serum creatinine, rate of ESRD, mean serum creatinine or $24 \mathrm{~h}$ proteinuria. This further confirmed that lower dose $C Y$ is an acceptable alternative for lupus induction.

7. •- Appel GB, Contreras G, Dooley MA, et al. Aspreva Lupus Management Study Group. Mycophenolate mofetil versus cyclophosphamide for induction treatment of lupus nephritis. J Am Soc Nephrol. 2009;20:1103-12. This is the largest randomized controlled trial to compare IV CY and MMF induction, with 370 ethnically and geographically diverse study subjects. Outcomes (remission and adverse events) were similar between groups. The study included 24 children (see reference 13 for details about this pediatric cohort).

8. Ginzler EM, Dooley MA, Aranow C, et al. Mycophenolate mofetil or intravenous cyclophosphamide for lupus nephritis. N Engl J Med. 2005;24:2219-28.

9. Houssiau FA, D’Cruz D, Sangle S, et al. MAINTAIN Nephritis Trial Group. Azathioprine versus mycophenolate mofetil for long-term immunosuppression in lupus nephritis: results from the MAINTAIN Nephritis Trial. Ann Rheum Dis. 2010;69:2083-9.

10. Dooley MA, Jayne D, Ginzler EM, et al. ALMS Group. Mycophenolate versus azathioprine as maintenance therapy for lupus nephritis. N Engl J Med. 2011;365:1886-95.
11. Koo HS, Kim YC, Lee SW, et al. The effects of cyclophosphamide and mycophenolate on end-stage renal disease and death of lupus nephritis. Lupus. 2011;20:1442-9.

12. Arends S, Grootscholten C, Derksen RH, et al. Dutch Working Party on systemic lupus erythematosus. Long-term follow-up of a randomised controlled trial of azathioprine/methylprednisolone versus cyclophosphamide in patients with proliferative lupus nephritis. Ann Rheum Dis. 2012;71:966-73.

13. - Sundel R, Solomons N, Lisk L. Efficacy of mycophenolate mofetil in adolescent patients with lupus nephritis: evidence from a two-phase, prospective randomized trial. Lupus. 2012;21: 1433-43. This is a separate analysis of the 24 children who were included in the ALMS study, and is the only randomized controlled data available in children to compare induction and maintenance regimens for SLE. It showed a non-significant trend towards benefit from MMF induction as well as MMF maintenance compared to AZA.

14. Pereira T, Abitbol CL, Seeherunvong W, Katsoufis C, Chandar J, Freundlich M, Zilleruelo G. Three decades of progress in treating childhood-onset lupus nephritis. Clin J Am Soc Nephrol. 2011;6:2192-9.

15. Isenberg D, Appel GB, Contreras G, et al. Influence of race/ ethnicity on response to lupus nephritis treatment: the ALMS study. Rheumatology. 2010;49:128-40.

16. Mohan S, Radhakrishnan J. Geographical variation in the response of lupus nephritis to mycophenolate mofetil induction therapy. Clin Nephrol. 2011;75:233-41.

17. Zavada J, Pesickova S, Rysava R, et al. Cyclosporine A or intravenous cyclophosphamide for lupus nephritis: the CyclofaLune study. Lupus. 2010;19:1281-9.

18. Griffiths B, Emery P, Ryan V, et al. The BILAG multi-centre open randomized controlled trial comparing ciclosporin vs azathioprine in patients with severe SLE. Rheumatology. 2010;49:723-32.

19. Austin HA 3rd, Illei GG, Braun MJ, Balow JE. Randomized, controlled trial of prednisone, cyclophosphamide, and cyclosporine in lupus membranous nephropathy. J Am Soc Nephrol. 2009;20:901-11.

20. Aragon E, Chan $\mathrm{YH}, \mathrm{Ng} \mathrm{KH}$, et al. Good outcomes with mycophenolate-cyclosporine-based induction protocol in children with severe proliferative lupus nephritis. Lupus. 2010;19:965-73.

21. Baca V, Catalán T, Villasís-Keever M, et al. Effect of low-dose cyclosporine $\mathrm{A}$ in the treatment of refractory proteinuria in childhood-onset lupus nephritis. Lupus. 2006;15:490-5.

22. Sakuma S, Kato Y, Nishigaki F, et al. FK506 potently inhibits T cell activation induced TNF-alpha and IL-1beta production in vitro by human peripheral blood mononuclear cells. $\mathrm{Br} \mathrm{J}$ Pharmacol. 2000;130:1655-63.

23. Deng J, Huo D, Wu Q, Yang Z, Liao Y. A meta-analysis of randomized controlled trials comparing tacrolimus with intravenous cyclophosphamide in the induction treatment for lupus nephritis. Tohoku J Exp Med. 2012;227:281-8.

24. Lee YH, Lee HS, Choi SJ, Dai Ji J, Song GG. Efficacy and safety of tacrolimus therapy for lupus nephritis: a systematic review of clinical trials. Lupus. 2011;20:636-40.

25. Wang S, Li X, Qu L, et al. Tacrolimus versus cyclophosphamide as treatment for diffuse proliferative or membranous lupus nephritis: a non-randomized prospective cohort study. Lupus. 2012;21:1025-35.

26. Chen W, Liu Q, Chen W, et al. Outcomes of maintenance therapy with tacrolimus versus azathioprine for active lupus nephritis: a multicenter randomized clinical trial. Lupus. 2012;21:944-52.

27. Li X, Ren H, Zhang Q, et al. Mycophenolate mofetil or tacrolimus compared with intravenous cyclophosphamide in the induction treatment for active lupus nephritis. Nephrol Dial Transplant. 2012;27:1467-72. 
28. Fernandez D, Bonilla E, Mirza N, et al. Rapamycin reduces disease activity and normalizes $\mathrm{T}$ cell activation-induced calcium fluxing in patients with systemic lupus erythematosus. Arthritis Rheum. 2006;2006:54.

29. Clinical Trials Registry. www.clinicaltrials.gov. Accessed Oct 2012.

30. Wang HY, Cui TG, Hou FF, et al. Induction treatment of proliferative lupus nephritis with leflunomide combined with prednisone: a prospective multi-centre observational study. Lupus. 2008; 17:638-44.

31. Xiong W, Lahita RG. Novel treatments for systemic lupus erythematosus. Ther Adv Musculoskelet Dis. 2011;3:255-66.

32. Steinmetz OM, Velden J, Kneissler U, et al. Analysis and classification of B-cell infiltrates in lupus and ANCA-associated nephritis. Kidney Int. 2008;74:448-57.

33. Reff ME, Carner K, Chambers KS, et al. Depletion of B cells in vivo by a chimeric mouse human monoclonal antibody to CD20. Blood. 1994;83:435-45.

34. •• Diaz-Lagares C, Croca S, Sangle S, et al. Efficacy of rituximab in 164 patients with biopsy-proven lupus nephritis: pooled data from European cohorts. Autoimmun Rev. 2012;11:357-64. This study evaluated the potential efficacy of Rituximab in refractory lupus nephritis. Pooled analysis from 164 European subjects noted significant improvement in proteinuria and serum albumin after treatment with Rituximab.

35. Fernandez-Nebro A, de la Fuente JM, Carreno L, et al. Multicenter longitudinal study of B-lymphocyte depletion in refractory systemic lupus erythematosus: the LESIMAB study. Lupus. 2012;21(1063):1-76.

36. • Rovin BH, Furie F, Latinis K, et al. Efficacy and safety of rituximab in patients with active proliferative lupus nephritis: the lupus nephritis assessment with rituximab study. Arthritis Rheum. 2012;64:1215-26. This double-blind placebo-controlled phase 3 trial with 144 patients is the first to evaluate efficacy and clinical outcomes of Rituximab in active lupus nephritis concomitantly treated with mycophenolate mofetil. Rituximab therapy did not show improvement in clinical outcomes at one year follow up.

37. • Merrill JT, Buyon JP, Furie RA, et al. Assessment of flares in lupus patients enrolled in a phase II/III study of rituximab (EXPLORER). Lupus. 2011;20:709-16. This double-blind placebo-controlled phase 3 trial with 257 patients examined the effects of Rituximab on lupus flare rates in moderately to severely affected SLE patients with extra-renal lupus manifestations. The study found no difference between the rituximab-treated groups and controls at 52 weeks.

38. FDA Alert for Rituximab (marketed as Rituxan). http://www.fda. gov/Drugs/DrugSafety/PostmarketDrugSafetyInformationfor PatientsandProviders/ucm109106.htm. Accessed Nov 2012.

39. Schmedt N, Andersohn F, Garbe E. Signals of progressive multifocal leukoencephalopathy for immunosuppressants: a disproportionality analysis of spontaneous reports within the US Adverse Event Reporting System (AERS). Pharmacoepidemiol Drug Saf. 2012;21:1216-20.

40. Genovese MC, Kaine JL, Lowenstein MB, et al. Ocrelizumab, a humanized anti-CD20 monoclonal antibody, in the treatment of patients with rheumatoid arthritis. Arthritis Rheum. 2008;58: 2652-61.

41. Manzi S, Sanchez-Guerrero J, Merrill JT, et al. Effects of belimumab, a B lymphocyte stimulator-specific inhibitor, on disease activity across multiple organ domains in patients with systemic lupus erythematosus: combined results from two phase III trials. Ann Rheum Dis. 2012;71:1833-8.

42. Navarra SV, Guzman RM, Gallacher AE, et al. Efficacy and safety of belimumab in patients with active systemic lupus erythematosus: a randomized placebo-controlled, phase 3 trial. Lancet. 2011;377:721-31.
43. Dorner T, Kaufmann J, Wegener WA, et al. Initial clinical trial of epratuzumab (humanized anti-CD22 antibody) for immunotherapy of systemic lupus erythematosus. Arthritis Res Ther. 2006;8:R74.

44. UCB News Press Release: new data from EMBLEM study shows pipeline drug Epratuzumab provided significant efficacy for patients suffering from moderate to severe systemic lupus erythematosus. http://hugin.info/133973/R/1424204/372863.pdf.

45. Horowitz DM, Furie RA. Abetimus sodium: a medication for the prevention of lupus nephritis flares. Expert Opin Pharmacother. 2009;10:1501-7.

46. Cardiel MH, Tumlin JA, Furie RA, et al. Abetimus sodium for renal flare in systemic lupus erythematosus: results of a randomized, controlled Phase III trial. Arthritis Rheum. 2008;58:2470-80.

47. Boumpas DT, Furie R, Manzi S, et al. A short course of BG9588 (anti-CD40 ligand antibody) improves serologic activity and decreases hematuria in patients with proliferative lupus glomerulonephritis. Arthritis Rheum. 2003;48:719-27.

48. Illei GG, Shirota Y, Yarboro $\mathrm{CH}$, et al. Tocilizumab in systemic lupus erythematosus: data on safety, preliminary efficacy, and impact on circulating plasma cells from an open phase 1 dosageescalation study. Arthritis Rheum. 2010;62:542-52.

49. $\mathrm{Xu} \mathrm{Z}$, Bouman-Thio E, Comisar $\mathrm{C}$, et al. Pharmacokinetics, pharmacodynamics, and safety of a human anti-IL6 monoclonal antibody (sirukumab) in healthy subjects in a first in-human study. Br J Clin Pharmacol. 2011;72:270-81.

50. Ahluwalia JP. Immunotherapy in inflammatory bowel disease. Med Clin North Am. 2012;96:525-44.

51. Aringer M, Houssaiu F, Gordon C, et al. Adverse events and efficacy of TNF-a blockade with infliximab in patients with systemic lupus erythematosus: long-term follow up of 13 patients. Rheumatology. 2009;48:1451-4.

52. Deepak P, Sifuentes H, Sherid M, et al. T-cell non-hodgkin's lymphomas reported to the FDS AERS with tumor necrosis factor-alpha (TNF-a) inhibitors: results of the REFURBISH study. Am J Gastroenterol. 2012. doi:10.1038/ajg.2012.334.

53. Merrill JT, Burgos-Vargas R, Westhovens R, et al. The efficacy and safety of abatacept in patients with non-life-threatening manifestations of systemic lupus erythematosus. Arthritis Rheum. 2010;62:3077-87.

54. Pestana JO, Grinyo JM, Vanrenterghem Y, et al. Three-year outcomes from the BENEFIT-EXT: a phase III study of belatacept versus cyclosporine in recipients of extended criteria donor kidneys. Am J Transplant. 2012;12:630-9.

55. Merrill JT, Wallace DJ, Petri M, et al. Safety profile and clinical activity of sifalimumab, a fully human anti-interferon alpha monoclonal antibody, in systemic lupus erythematosus: a phase 1, multicenter, double blind randomized study. Ann Rheum Dis. 2011;70:1905-13.

56. Yao Y, Richman L, Higgs BW, et al. Neutralization of interferon$\mathrm{a} / \mathrm{b}$-inducible genes and downstream effect in a phase I trial of an anti-interferon-a monoclonal antibody in systemic lupus erythematosus. Arthritis Rheum. 2009;60:1785-96.

57. McBride JM, Jiang J, Abbas AR, et al. Safety and pharmacodynamics results of rontalizumab in a phase 1 , placebo controlled, double blind, dose-escalation study in systemic lupus erythematosus. Arthritis Rheum. 2012;64(11):3666-76.

58. Kaliyaperumal A, Michaels MA, Datta SK. Antigen-specific therapy of murine lupus nephritis using nucleosomal peptides: tolerance spreading impairs pathogenic function of autoimmune T and B cells. J Immunol. 1999;162:5775-83.

59. Muller S, Monneauz F, Schall N, et al. Spliceosomal peptide P140 for immunotherapy of systemic lupus erythematosus. Arthritis Rheum. 2008;58:3873-83.

60. Immupharma: Lupuzor-treatment for Lupus. http://www.immu pharma.org/lupuzor. Accessed Nov 2012. 
61. Mascarenhas S, Avalos B, Ardoin SP. An update on stem cell transplantation in autoimmune rheumatologic disorders. Curr Allergy Asthma Rep. 2012;12(6):530-40. This paper reviews autologous stem cell transplantation in a variety of rheumatologic disorders including SLE.

62. Jayne D, Passweg J, Marmont A, et al. Autologous stem cell transplantation for systemic lupus erythematosus. Lupus. 2004; 13:168-76.

63. Marmont A. Allogeneic hematopoietic stem cell transplantation for severe autoimmune diseases: great expectations but controversial evidence. Bone Marrow Transplant. 2006;38:1-4.

64. Stagg J, Galipeau J. Immune plasticity of bone marrow-derived mesenchymal stromal cells. Handb Exp Pharmacol. 2007;150: 45-66.

65. Sun L, Wang D, Liang J, et al. Umbilical cord mesenchymal stem cell transplantation in severe and refractory systemic lupus erythematosus. Arthritis Rheum. 2010;62:2467-75.

66. Tse WT, Pendleton JD, Beyer WM, et al. Suppression of allogeneic T-cell proliferation by human marrow stromal cells: implications in transplantation. Transplantation. 2003;75:389-97.

67. Talaulikaur D, Tymms KE, Prosser I, et al. Autologous peripheral blood stem cell transplantation with in vivo T-cell depletion for life threatening refractory systemic lupus erythematosus. Lupus. 2005;14:159-63.

68. Moore J, Brooks P, Milliken S, et al. A pilot randomized trial comparing CD34-selected versus unmanipulated hematopoietic stem cell transplantation for severe refractory rheumatoid arthritis. Arthritis Rheum. 2002;46:2301-9.

69. Burt RK, Traynor A, Statkute L, et al. Nonmyeloablative hematopoietic stem cell transplantation for systemic lupus erythematosus. JAMA. 2006;295:527-35.

70. Euler HH, Marmont AM, Bacigalupo A, et al. Early recurrence or persistence of autoimmune diseases after unmanipulated autologous stem cell transplantation. Blood. 1996;88:3621-5.

71. Illei GG, Cervera R, Burt RK, et al. Current state and future directions of autologous hematopoietic stem cell transplantation in systemic lupus erythematosus. Ann Rheum Dis. 2011;70: 2071-4.

72. Burt RK, Marmont A, Oyama Y, et al. Randomized controlled trials of autologous hematopoietic stem cell transplantation for autoimmune diseases: the evolution from myeloablative to lymphoablative transplant regimens. Arthritis Rheum. 2006;54: 3750-60.

73. •• Wakasugi D, Gono T, Kawaguchi Y, et al. Frequency of class III and IV nephritis in systemic lupus erythematosus without clinical renal involvement: an analysis of predictive measures. J Rheumatol. 2012;39:79-85. Prospective review of 195 patients with SLE stratified by clinical evidence of renal disease. No overt renal disease was defined as eGFR $>67 \mathrm{~mL} / \mathrm{min} / 1.73 \mathrm{~m}^{2}$, proteinuria $<400 \mathrm{gm} /$ day, and an inactive urinary sediment. Biopsy showed higher than WHO Class I lupus nephritis in $58 \%$ of the 86 patients without overt renal involvement. Although these patients had lower serum C3 complement levels and higher ds-DNA antibody titers than patients without changes on biopsy, this suggests that many of our present laboratory markers for detecting renal involvement are inadequate.

74. Marks SD, Williams SJ, Tullus K, et al. Glomerular expression of monocyte chemoattractant protein-1 is predictive of poor renal prognosis in pediatric lupus nephritis. Nephrol Dial Transplant. 2008;23:3521-6.

75. Rovin BH, Song H, Birmingham DJ, et al. Urine chemokines as biomarkers of human systemic lupus erythematosus activity. J Am Soc Nephrol. 2005;16:467-73.
76. Singh $\mathrm{S}$, Wu T, Xie C, et al. Urine VCAM-1 as a marker of renal pathology activity index in lupus nephritis. Arthritis Res Ther. 2012; 14:R164.

77. - Watson L, Midgley A, Pilkington C, et al. Urinary monocyte chemoattractant protein 1 and alpha 1 acid glycoprotein as biomarkers of renal disease activity in juvenile-onset systemic lupus erythematosus. Lupus. 2012;21:496-501. Urinary MCP-1 levels in children with SLE were compared to levels in healthy pediatric controls. Urinary MCP-1 levels were higher in those with active lupus determined by disease activity scores

78. Marks SD, Shah V, Pilkington C, et al. Urinary monocyte chemoattractant protein-1 correlates with disease activity in lupus nephritis. Pediatr Nephrol. 2010;25:2283-8.

79. Kjeldsen L, Cowland JB, Borregaard N. Human neutrophil gelatinase-associated lipocalin and homologous proteins in rat and mouse. Biochim Biophys Acta. 2000;1482:272-83.

80. Goetz DH, Holmes MA, Borregaard N, et al. The neutrophil lipocalin NGAL is a bacteriostatic agent that interferes with siderophore-mediated iron acquisition. Mol Cell. 2002;10:1033-43.

81. Parikh CR, Devarajan P, Zappitelli M, et al. TRIBE-AKI Consortium. Postoperative biomarkers predict acute kidney injury and poor outcomes after pediatric cardiac surgery. J Am Soc Nephrol. 2011;22:1737-47.

82. Brunner HI, Mueller M, Rutherford C, et al. Urinary neutrophil gelatinase-associated lipocalin as a biomarker of nephritis in childhood-onset systemic lupus erythematosus. Arthritis Rheum. 2006;54:2577-84.

83. Suzuki M, Wiers KM, Klein-Gitelman MS, et al. Neutrophil gelatinase-associated lipocalin as a biomarker of disease activity in pediatric lupus nephritis. Pediatr Nephrol. 2008;23:403-12.

84. Hinze CH, Suzuki M, Klein-Gitelman M, et al. Neutrophil gelatinase-associated lipocalin is a predictor of the course of global and renal childhood-onset systemic lupus erythematosus disease activity. Arthritis Rheum. 2009;60:2772-81.

85. Daniel L, Sichez H, Giorgi R, et al. Tubular lesions and tubular cell adhesion molecules for the prognosis of lupus nephritis. Kidney Int. 2001;60:2215-21.

86. Abd-Elkareem MI, Al Tamimy HM, Khamis OA, et al. Increased urinary levels of the leukocyte adhesion molecules ICAM- 1 and VCAM-1 in human lupus nephritis with advanced renal histological changes: preliminary findings. Clin Exp Nephrol. 2010; 4:548-57.

87. Suzuki M, Ross GF, Wiers K, et al. Identification of a urinary proteomic signature for lupus nephritis in children. Pediatr Nephrol. 2007;22:2047-57.

88. Suzuki M, Wiers K, Brooks EB, et al. Initial validation of a novel protein biomarker panel for active pediatric lupus nephritis. Pediatr Res. 2009;65:530-6.

89. - Brunner HI, Bennett MR, Mina R, et al. Association of noninvasively measured renal protein biomarkers with histologic features of lupus nephritis. Arthritis Rheum. 2012;64:2687-97. Describes success using combination biomarkers to detect histological characteristics and disease activity in 76 patients (including 26 children). MCP-1, AAG, CP and UPC predicted lupus activity (AUC 0.85) and MCP-1, NGAL, and $\mathrm{CrCl}$ had an $A U C$ of 0.83 for chronicity, and MCP-1, AAG, TF, CrCl and C4 had an AUC of 0.75 for detecting membranous $L N$.

90. Zhang X, Nagaraja HN, Nadasdy T, et al. A composite urine biomarker reflects interstitial inflammation in lupus nephritis kidney biopsies. Kidney Int. 2012;81:401-6. 